\title{
Selection into Auctions for Risky and Ambiguous Prospects
}

\section{by Martin G. Kocher* and Stefan T. Trautmann $^{\dagger}$}

${ }^{*}$ School of Economics, University of East Anglia, United Kingdom

${ }^{\dagger}$ Tilburg Institute for Behavioral Economics Research, Department of Social Psychology \& CentER, Tilburg University, The Netherlands

\begin{abstract}
We study experimentally the selection into first-price sealed-bid auctions for a risky or an ambiguous prospect. Most subjects chose to submit a bid for the risky prospect, leading to thinner markets for the ambiguous prospect. Transaction prices for both prospects were equal although subjects expected the ambiguous markets to be smaller. Evidence of a positive correlation between risk and ambiguity aversion suggests that the ambiguous markets were populated by relatively risk tolerant bidders. A control experiment with selection in a simple choice task shows that subjects correctly anticipate the effects of selection on market size and risk attitudes.
\end{abstract}

\section{JEL classification codes}

C91, D44, D81

\section{Keywords}

auction, experiment, risk aversion, ambiguity aversion, market prices

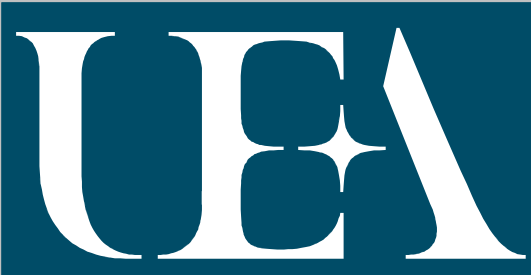

University of East Anglia

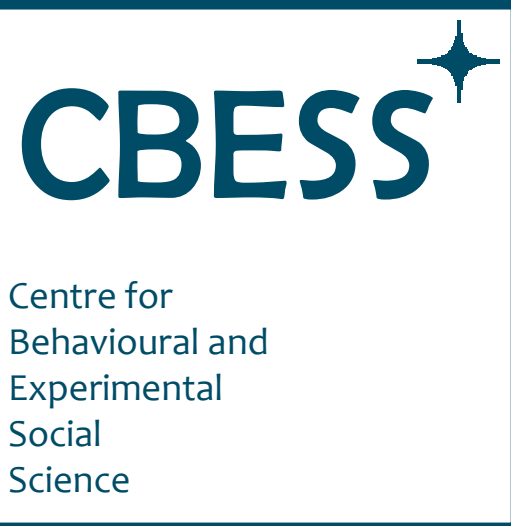

Social

Science

\section{CBESS}

University of East Anglia Norwich NR4 7TJ

United Kingdom www.uea.ac.uk/ssf/cbess 
Corresponding author's address: School of Economics, University of East Anglia, Norwich, NR4 7TJ. United Kingdom. m.kocher@uea.ac.uk.

We thank Theo Offerman, Jan Potters, Peter P. Wakker, Richard Zeckhauser and seminar participants at the Decision and Uncertainty Workshop 2007, the ESA world meeting 2007, FUR 2008, IMEBE 2008, GTS 2008, Colorado State University, the Dutch Central Bank, the University of Innsbruck, the University of Ulm, and the ENABLE symposium 2008 in Amsterdam for helpful suggestions. We gratefully acknowledge financial support from the ENABLE Project under the European Union 6th Framework Program. The paper reflects the views of the authors, and the European Union is not liable for any use that may be made of the information contained herein. 


\section{Introduction}

In decisions under uncertainty people have been found to prefer prospects involving known probabilities (risky prospects) to prospects with unknown probabilities (ambiguous prospects), even if expected utility theory (Savage 1954) prescribes indifference. This phenomenon is called ambiguity aversion (Ellsberg 1961). The idea that agents treat decisions under risk differently from decisions under ambiguity dates back to Keynes (1921) and Knight (1921), and numerous studies have demonstrated the empirical relevance of ambiguity aversion. People are often willing to forgo significant amounts of money to avoid ambiguous prospects in favor of risky prospects that are equivalent under expected utility (Charness and Gneezy 2010, Gilboa 2004, Halevy 2007, Sarin and Weber 1993).

In the real world, decisions under uncertainty often involve only vague probabilities, making ambiguity aversion a possible cause for observed market phenomena which are anomalies from the point of view of expected utility theory. Ambiguity aversion has been incorporated in theoretical models to explain such anomalies. Examples include the home bias in investment (Uppal and Wang 2003; Huang 2007), voluntary tax compliance (Snow and Warren 2005), and consumer preferences for established brands (Muthukrishnan, Wathieu, and $\mathrm{Xu}, 2009)$.

There is, however, little direct evidence of the effect of individual ambiguity attitudes on market outcomes and, vice versa, of the effect of market interaction and market institutions on ambiguity attitudes. In this paper, we study the effect of selection into simple auction markets for risky and ambiguous prospects on market prices and market sizes in two experiments. Consider two auctions, one of them providing a risky asset and one of them providing an ambiguous asset. We investigate a situation in which agents can participate in only one of the two auctions because of capacity or budget constraints, sunk costs of information acquisition, or legal participation restrictions. In such a context, we particularly analyze (i) the selfselection into markets depending on risk attitudes, ambiguity attitudes and expectations, (ii) the effect of the market institution on prices, and (iii) the correlation of risk and ambiguity attitudes and its effects on the market outcome. ${ }^{1}$

\footnotetext{
1 Ivanova-Stenzel and Salmon $(2004,2008)$ study selection in auctions and the role of beliefs about other bidders' risk attitudes. In contrast to our paper, they consider selection into different auction formats (ascending vs. first-price sealed bid) for a given item, and fixed market size of two bidders.
} 
Recent applications of ambiguity to financial regulation and investment behavior emphasize the effect of ambiguity aversion on self-selection and market size (Easley and O'Hara 2009; Zeckhauser 2006). Ambiguity averse agents shy away from markets for ambiguous investments, leading to reduced competition and lower prices. Often capacity constraints and participation restrictions exist in markets, for instance in simultaneous procurement bidding for multiple projects (Iyer and Pazgal 2008), allowing agents to operate only in one market. In such settings we expect strong selection effects if the agents have to choose between markets of different levels of ambiguity. With selection, additional strategic considerations become relevant. If market participants expect competitors to stay out of ambiguous markets, then there is an incentive for them to enter these markets even if they preferred less ambiguous markets otherwise.

Our results support these predictions: We find that selection affects market outcomes through risk and ambiguity attitudes and through subjects' expectations of other participants' risk and ambiguity attitudes. The results also show that heterogeneity in risk and ambiguity attitudes becomes important because of a positive correlation between these attitudes that makes the effect of ambiguity on prices dependent on the market institution. ${ }^{2}$

Markets for risky and ambiguous prospects have also been studied by Sarin and Weber (1993) and more recently by Bossaerts et al. (2007). Bossaerts et al. let their experimental subjects trade securities with state-dependent payoffs where state probabilities were either risky or ambiguous. They find that equilibrium prices and security holdings are affected by ambiguity and suggest a positive correlation between ambiguity aversion and risk aversion, consistent with our result. Sarin and Weber report higher prices for risky prospects in firstprice sealed-bid auctions and oral double auction markets. In their experiment there was no selection and all subjects bid in all markets. Considering their institutional setup, we will be able to add to the understanding of their results with the findings from our paper.

Camerer and Kunreuther (1989) study ambiguity aversion in insurance markets, i.e. the loss domain, and operationalize ambiguity through compound lotteries (second-order probabilities). Consistent with individual choice evidence on ambiguity attitude for losses (Hogarth and Kunreuther 1985), this insurance market study does not find effects of

\footnotetext{
${ }^{2}$ Easley and O'Hara (2009) show that heterogeneity of ambiguity attitudes can affect asset markets also if all agents have identical risk attitudes. In their model, ambiguity aversion leads to smaller markets and suboptimal risk sharing.
} 
ambiguity. In contrast, we use Ellsberg-type uncertainty in the gain domain in our experiments.

In section 2 we review theoretical results in the literature on first price auctions with uncertain payoffs and ambiguity and derive hypotheses for the market setting with selection that is examined in our paper. Sections 3 and 4 present our main experiment in which we offer a large group of subjects the choice to bid from their own money for either a risky or an ambiguous prospect, using first-price sealed-bid auctions. That is, subjects had to choose between either of two auctions and could bid only once. As a real world analog consider the simultaneous auctioning of multiple oil tract leases in different regions. Some tracts might carry more ambiguous risks than others and each company can only bid for one lease because of capacity constraints to exploit tracts. ${ }^{3}$ In the housing market, a similar situation arises when potential buyers have to decide for which of several houses they want to make a bid. A house located in an established neighborhood could exhibit less ambiguous risks (such as the level of criminal activity in the neighborhood, for which statistics are readily available) than a house in a newly developed suburb for which there is little data yet.

In our experiment we observe strong ambiguity aversion leading to thinner markets for the ambiguous prospect, but equal transaction prices (maximum bids) for risky and ambiguous prospects. Using a measure of risk attitude from an unrelated decision task, we find that bidders in the market for the ambiguous prospect are less risk averse than those in the market for the risky prospect.

With such sorting in terms of risk attitudes, subjects' expectations about market sizes and about the other bidders' risk attitudes in the two markets affect choices. To isolate the effect of expectations about market size from expectations about sorting, we conduct a control experiment which we discuss in Section 5. In a simple choice task one person from the group choosing risky and one person from the group choosing ambiguous is randomly selected for real play. This setting is similar to lotteries for affordable housing. Eligible families can enter a lottery for the right to rent or buy a house at below the market rate, but may be constrained to submit only a limited number of applications. Houses may differ in the ambiguity of the risks they carry. While the family in the above described auction situation should clearly consider both the number and the aggressiveness of their competitors, the family in the

\footnotetext{
${ }^{3}$ These risks are assumed to be independent of possible uncertainty about the yield of the tract and the signals thereof, like political or environmental risk as modeled in Esö and White (2004).
} 
housing lottery need only consider their expectations about how many people enter the lotteries for different houses. We find that with such pure size incentives the markets for the ambiguous prospect are no longer thinner that those for the risky prospect, consistent with the strategic incentives for subjects who expect a majority choice of the risky market.

Finally, section 6 discusses our results and relates them to the literature. In this section we also review the evidence about the correlation between risk as well as ambiguity attitude and address implications of our results.

\section{Theory and Hypotheses}

Theoretical accounts of first price auctions mostly assume sure payoffs from winning the auction and common knowledge of the distribution of the payoffs over market participants. Risk attitudes and market size, then, affect market outcomes through their effect on the optimal shading of bids (Cox, Smith and Walker 1982, 1985). There have been extensions of the basic paradigm to either account for potentially risky payoffs from the auction, or to account for ambiguity.

Esö and White (2004) extend the basic model to allow for risky payoffs from the auction that are independent of possible common value components. That is, they study pure ex-post risk that is known to all agents, and is considered by the agents in their bids. Esö and White show that under decreasing absolute risk aversion the ex-post risk leads to a decrease in the bids by more than the risk premium, an effect they call precautionary bidding. Chen, Katuscak and Ozdenoren (2007) as well as Salo and Weber (1995) study auctions where the distribution of payoffs is ambiguous but the payoffs themselves are certain. The intuition of these models is that the distribution of private values will not precisely be known by bidders in real world situations and, hence, they have to form ambiguous beliefs about it. Both studies show that ambiguity aversion reduces bid shading and can therefore explain overbidding in first price auctions. Similarly, Jamison and Karlan (2009) find that ambiguity averse bidders prefer to bid in auctions where the distribution of buyer values is common knowledge. There are no results yet regarding the extension of these findings to the situation where payoffs are also ambiguous.

While the effect of the additional uncertainty component will depend on the assumed model for decision under ambiguity, the above discussed results by Esö and White also 
suggest that bids should at least be reduced by the risk and by the ambiguity premium. Salo and Weber find that the effect of reduced bid shading as the number of bidders increases carries over to situations under ambiguity. Moreover, ambiguity about the number of bidders reduces bid shading under ambiguity aversion.

Our setting with auctions for prospects that differ in their degree of ambiguity, and the agents selecting into these markets according to their ambiguity attitudes, combines features of both these streams of research. Because private values depend on the unknown risk and ambiguity premiums of other bidders, the distribution of private values is also ambiguous. Market sizes are not fixed, making the number of bidders ambiguous.

Equilibria in our settings will be complex, especially given the asymmetry of bidders. If preferences and beliefs are correlated, e.g. if ambiguity averse agents believe that other bidders have a similar dislike for ambiguity, theoretical models will have a hard time to predict market behavior. In this paper we do not aim to introduce a theoretical account of selection into auctions with ambiguous payoffs, but to study empirically whether results from basic settings hold also if agents self-select into risky and ambiguous auctions. In particular, we want to test two hypothesis regarding price and size effects of ambiguity on markets, that extrapolate results from individual decision settings and auctions without selection as in Sarin and Weber (1993). We are particularly interested in behavior in one-shot situations, because with repeated interaction in an ambiguous market its ambiguity is most likely reduced over time.

Assume two first-price sealed-bid auctions for a risky and an ambiguous prospect that are equivalent under expected utility. Subjects can only submit one bid, that is, they have to decide in which of the two auctions they want to participate. Subject can only submit a bid once. We state the following two hypotheses:

Hypothesis 1: The transfer price for an ambiguous prospect will be lower than the transfer price of a risky prospect that is equivalent under expected utility.

Numerous studies have shown that subjects' willingness to pay for ambiguous prospects is much lower than for prospects with well defined probabilities. This has been found to be true also for market prices. Hypothesis 1 tests whether this effect also obtains in a market setting with selection. 
Hypothesis 2: The number of bidders for the ambiguous prospect will be lower than the number of bidders for the risky prospect.

In equilibrium, agents should be indifferent between submitting a bit for either auction and depending on subjects' preferences and beliefs, various distributions of bidders over the two auctions might form an equilibrium. Under the widely observed pessimistic attitudes toward the prize in the ambiguous market, we expect that convergence to an equilibrium would be attained from a situation with too few bids for the ambiguous prospect. In a oneshot selection situation, this suggests fewer bids for the ambiguous than for the risky auction.

If agents strategically bid for ambiguous options even if they are otherwise ambiguity averse, however, we expect that indicators of ambiguity aversion in terms of price and market size will not be observed, implying a rejection of the hypotheses. In this case we expect an important role of expectations and the interaction of beliefs and preferences for predicting market outcomes (Haruvy, Lahav and Noussair 2007).

\section{Experiment 1 (Main Experiment): Design}

Subjects. One hundred and seventy-six undergraduate students participated in eight laboratory sessions. In each session there were between 20 and 24 subjects. Students were recruited electronically from a pool of approximately 1200 potential participants and came from different fields of study. Each subject participated only once.

Payoffs. Each subject received a show-up payment of $€ 5$. In each session, two subjects could participate in a prospect that paid $€ 30$ in case of success and $€ 0$ otherwise. These two persons were determined by an auction. Each subject could bid from his or her own money for the right to play one of the two prospects. The two winners in each session had to pay their own bid immediately before playing. Subjects could also earn between zero and $€ 200$ from a risky decision task that preceded the auction. At the time of the auction subjects did not know how much they would win from the risky decision task. The auction experiment took approximately 30 minutes. 
Procedure. Upon arriving at the laboratory subjects were randomly assigned to computers that are placed in individual cubicles. All parts of the experiment were computerized using the experimental software z-tree (Fischbacher 2007). All randomizations of prospects were conducted by throwing dice or drawing chips from a bag, at the subjects' desks. Subjects first made decisions in the risky choice task. One decision would be selected for real payment, and the payoffs depended on subjects' choices and chance. All subjects faced exactly the same decision tasks but the payoff-relevant task was chosen independently for each subject. Before the payoff-relevant decision was selected for each subject and the payoffs determined according to the subjects' choices, we offered subjects the possibility to participate in a firstprice sealed-bid auction for one of two prospects. At this point subjects had no information about their earnings from the risky decision task but each subject had received $€ 5$ for showing up on time. We offered to each group of 20 to 24 subjects the following two lottery options that represented the risky and the ambiguous urn in the Ellsberg (1961) two-color choice task: ${ }^{4}$

“Option A gives you a draw from a bag that contains exactly 20 red and 20 green poker chips. Before you draw, you choose a color and announce it to the experimenter. Then you draw. If the color you announced matches the color you draw, you win $€ 30$. If the colors do not match, you get nothing."

“Option B gives you a draw from a bag that contains exactly 40 poker chips. They are either red or green, in an unknown proportion. Before you draw, you choose a color and announce it to the experimenter. Then you draw. If the color you announced matches the color you draw, you win $€ 30$. If the colors do not match, you get nothing."

Option A offers a risky prospect with a probability of 50\% for each color to be drawn. Option B offers an ambiguous prospect because the probabilities for each color to be drawn are unknown. Subjects had to choose the winning color, and it was clear that the experimenter had no possibility to influence the outcome of either option. If subjects are indifferent between betting on either color in option $\mathrm{B}$, the two options are equivalent under expected

\footnotetext{
${ }^{4}$ The description of the two options is taken from the instructions that were used in the laboratory. Complete instructions can be found in the Appendix.
} 
utility. If subjects believe that there are more than 20 red chips in option $\mathrm{B}$, this option is preferred to option A because it offers a higher expected utility by betting on red. A similar argument holds if subjects believe that there are more than 20 green chips in option $\mathrm{B}$. The order and the letter for the two options in the instructions and on the computer screens were counterbalanced in half of the sessions.

It was explained to the subjects that only one option A and one option B was offered to the whole group and that two persons were determined by an auction to play the prospects, one for each prospect. Each subject could place a bid for either the risky option A or the ambiguous option $\mathrm{B}$. This was done at the computer by choosing one option and placing a bid for that option. Subjects could only submit one bid. After the auction winners were determined, they would immediately pay their bid from their own cash and play the prospects at their desks. It was made clear to subjects that they could not use any advances from possible earnings from the experiment to pay their bid. Any bid between $€ 0$ and $€ 30$ could be submitted and change was available. ${ }^{5}$

The one-shot auction design is applied because of the inherent uniqueness of ambiguous situations and because it avoids possible biases in learning with repeated auctions. Previous studies have shown that feedback on other participants' bids affects bidding in repeated auctions when resale values of the prize are certain (Duwfenberg and Gneezy 2002, Neugebauer and Selten 2006). In particular, information about winning bids leads to overbidding. With risky and ambiguous prospects as prizes such effects may be even stronger, and they may potentially be different for the two prospects. Learning through repeated bidding with an immediate resolution of the prospects, on the other hand, is impossible with ambiguous prospects because subjects would learn about the probabilities of the ambiguous option, therefore eliminating the ambiguity.

After submitting their bid, but before learning the maximum bid in the auction in which they participated and whether they were the winner of this auction, subjects answered questions regarding their expectation of how many people would choose the auction for option $\mathrm{A}$, and the expectation about their chances to win the $€ 30$ if they were simply playing option B. The latter question was included to elicit a matching probability and measure

\footnotetext{
${ }^{5}$ Participants might have been subjected to budget constraints in our setup. It is unlikely that budget constraints in the range relevant here correlate with risk and ambiguity attitudes. Providing the endowment necessary to avoid any budget constraints in bidding seemed more likely to affect uncertainty attitudes.
} 
ambiguity aversion outside the auction setting (Kahn and Sarin 1988). Both questions offered five brackets of $20 \%$ as answers: "less than 20\%", "between $20 \%$ and $40 \%$ ", "between $40 \%$ and $60 \%$ ", "between $60 \%$ and $80 \%$ ", and "more than $80 \% "$ ". These wide brackets were chosen to make the task relatively easy for students and avoid any prominence of the $50 \%$ probability. The choices were scored on a five-point scale with 1 referring to the bracket with the smallest expected probability ("less than $20 \% "$ ").

Subjects knew the size of the whole group. Experimental instructions were distributed individually and read aloud to the subjects. Remaining questions were answered privately. After playing the prospects, the experimental earnings from the other decision task were determined. Subjects filled out a short demographic questionnaire, were paid for the other task and dismissed from the laboratory.

Risk attitudes. In the first part of the experiment subjects made choices between risky prospects. To compare subjects' risk attitudes we constructed a measure of risk aversion from six choices between sure payoffs and risky prospects. Three of the decision problems offer a choice between a risky prospect and its expected value (problems 1 to 3 ). The other three decision problems are adapted from prospect choices for which a preference of roughly $50 \%$ for each option has been found in previous studies (problems 4 to 6), and these choices are therefore likely to distinguish well between subjects (Wakker, Timmermans and Machielse 2007). Our measure of individual risk aversion is the number of safe choices in the six decisions made by a subject. The six prospects are displayed in Table 1, with $x$ denoting a sure payoff and $(x, p ; y)$ denoting a prospect that pays $x$ with probability $p$ and pays $y$ with probability $1-p$.

Table 1: Decisions Problems for Risk Attitude Measurement

\begin{tabular}{lcccccc}
\hline \hline & \multicolumn{5}{c}{ Risky decision problem } \\
\cline { 2 - 6 } $\begin{array}{l}\text { Sure } \\
\text { option }\end{array}$ & $€ 10$ & $€ 13$ & $€ 12$ & $€ 14$ & $€ 13$ & $€ 11$ \\
$\begin{array}{l}\text { Risky } \\
\text { option }\end{array}$ & $€ 20,0.5 ; € 0$ & $€ 52,0.25 ; € 0$ & $€ 15,0.8 ; € 0$ & $€ 18,0.95 ; € 0$ & $€ 32,0.5 ; € 0$ & $€ 200,0.05 ; € 0$ \\
\hline \hline
\end{tabular}


The prospects were played by the subjects for real payoffs using the random incentive lottery mechanism (Holt and Laury 2002; Starmer and Sugden 1991; van de Kuilen 2009). Note that the $€ 30$ prize of the prospects sold in the auction lies within the range of payoffs of the prospects we use to measure individual differences in risk attitude.

We decided not to elicit individual ambiguity attitudes before the main experiment. While both prospects offered in the auctions involve risk and should therefore similarly be affected by the experience that subjects had from making risky decisions in the first part, only one of the prospects is ambiguous. Eliciting ambiguity attitudes in the first part may therefore asymmetrically affect the decisions in the two auctions in our main experiment, making additional controls for the order of event necessary.

\section{Experiment 1: Results and Discussion}

\subsection{Results}

Auction Outcomes. We find strong ambiguity aversion in our auction markets. Only 65 of 176 subjects $(37 \%)$ chose to bid for the ambiguous prospect ( $\mathrm{p}=0.001$, binomial test). The details of the eight individual sessions are summarized in Table 2 (Panel A) and Figure 1.

The number of bidders in the auction for the ambiguous prospect is smaller than the number of bidders in the auction for the risky prospect in seven out of eight sessions, and once it is equal. The percentage of bids for the ambiguous prospect ranges from $14 \%$ to $50 \%$, making markets for the ambiguous prospect significantly thinner than markets for the risky prospect ( $\mathrm{p}=0.003$, Mann-Whitney test).

Larger markets for the risky prospect should, everything else equal, lead to higher transaction prices (maximum bids): it is more likely that a high-value bidder is in the market, and if participants correctly anticipate strong competition they will shade their bids less. Although competition is much lower for the ambiguous prospect, transaction prices are equal for both prospects. The transaction price of the ambiguous prospect is higher than the price for the risky prospect in four out of eight sessions, and average transaction prices for the two options do not differ ( $\mathrm{p}=0.834$, Mann-Whitney test). This result is based on the observation of eight markets, but strong support comes from the analysis of the individual bids. The average and median bids are slightly higher for the ambiguous prospect with a mean of $€ 4.30$ (median 
$€ 4.00$ ), compared to a mean of $€ 3.43$ (median $€ 3.05$ ) for the risky prospect ( $p=0.039$, MannWhitney test).

Table 2: Auction Outcomes per Session

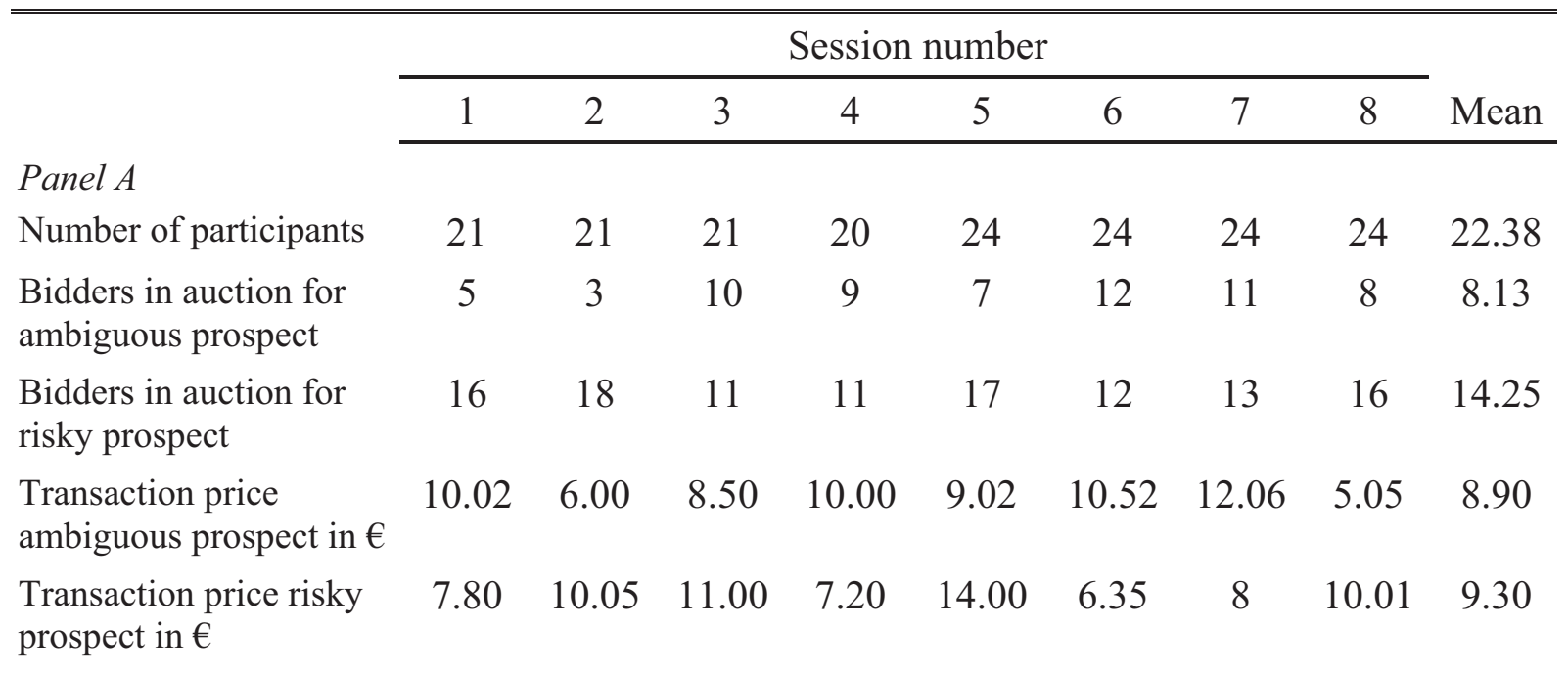

\section{Panel B}

$\begin{array}{llllllllll}\text { Average risk aversion } & 2.2 & 2.3 & 2.9 & 3.2 & 3.7 & 2.6 & 3.7 & 3.8 & 3.05\end{array}$
ambiguous auction*

$\begin{array}{llllllllll}\text { Average risk aversion } & 3.5 & 3.7 & 3.6 & 3.7 & 4 & 4.5 & 3.7 & 4.3 & 3.88\end{array}$
risky auction*

*Number of safe choices in six risky choice problems shown in Table 1.

Figure 1: Auction Outcomes per Session

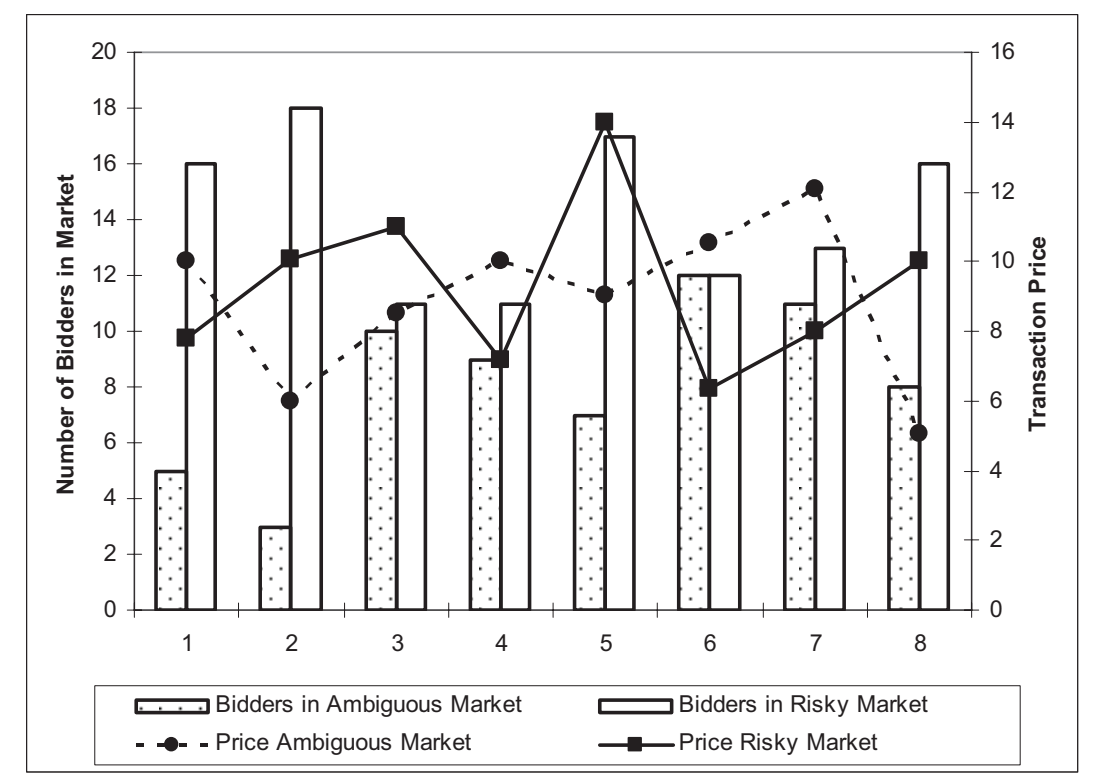


Figure 2 shows the distribution of bids for both options. Small bids $(\leq € 2)$ are much more frequent in the auction for the risky prospect and large bids $(>€ 8)$ are more frequent in the auction for the ambiguous prospect. This observation suggests that there is a segmentation of subjects with different risk attitudes into the two markets, with less risk averse subjects choosing to bid for the ambiguous prospect.

The data from the independent risk attitude measurement confirm that subjects in the risky auctions were more risk averse on average than subjects in the ambiguous auctions ( $p=0.001$, Mann-Whitney test). Table 2 (Panel B) shows that the average risk aversion in the ambiguous auctions was smaller in seven of the eight sessions. Figure 3 gives the distribution of the number of safe choices for both options. Extreme levels of risk aversion with five or six risk averse choices are much more common for subjects in the auction for the risky prospect, and risk seeking behavior with zero or one risk averse choice only is more common for subjects bidding for the ambiguous prospect. The probit regression in Model I of Table 3 shows that each risk averting choice increases the probability that a subject bids for the risky option by 7 percentage points, controlling for gender. The effect of risk attitudes is robust if we control for expectations about competition and for attitudes toward the ambiguous prospect (Table 3, Model II).

Figure 2: Distribution of Bids

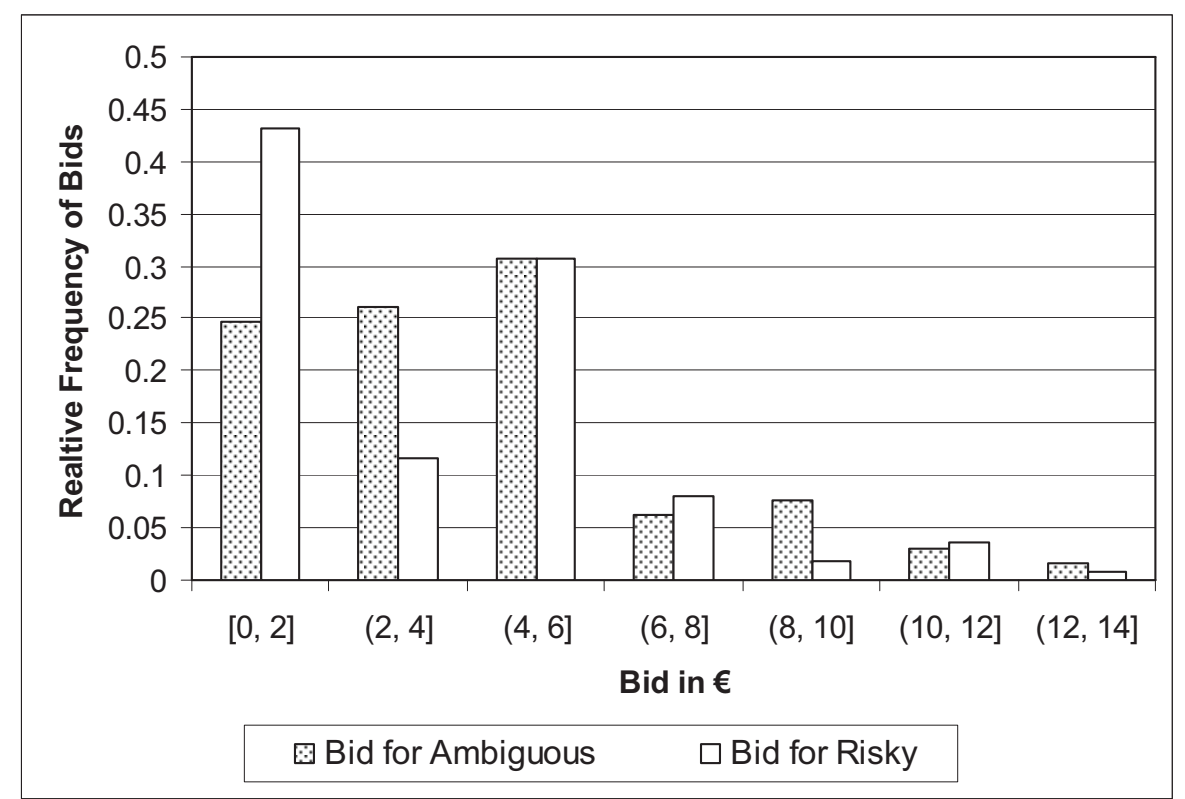


If selection of relatively risk tolerant subjects into the ambiguous prospect's auction contributes to the equality of prices in the two auctions, we would expect lower bids from more risk averse subjects. Linear regression results in Model III of Table 3 show that more risk averse subjects indeed submit lower bids in their auctions. Each risk averting choice decreases a subject's bid by $€ 0.37$.

Figure 3: Distribution of Risk Attitudes

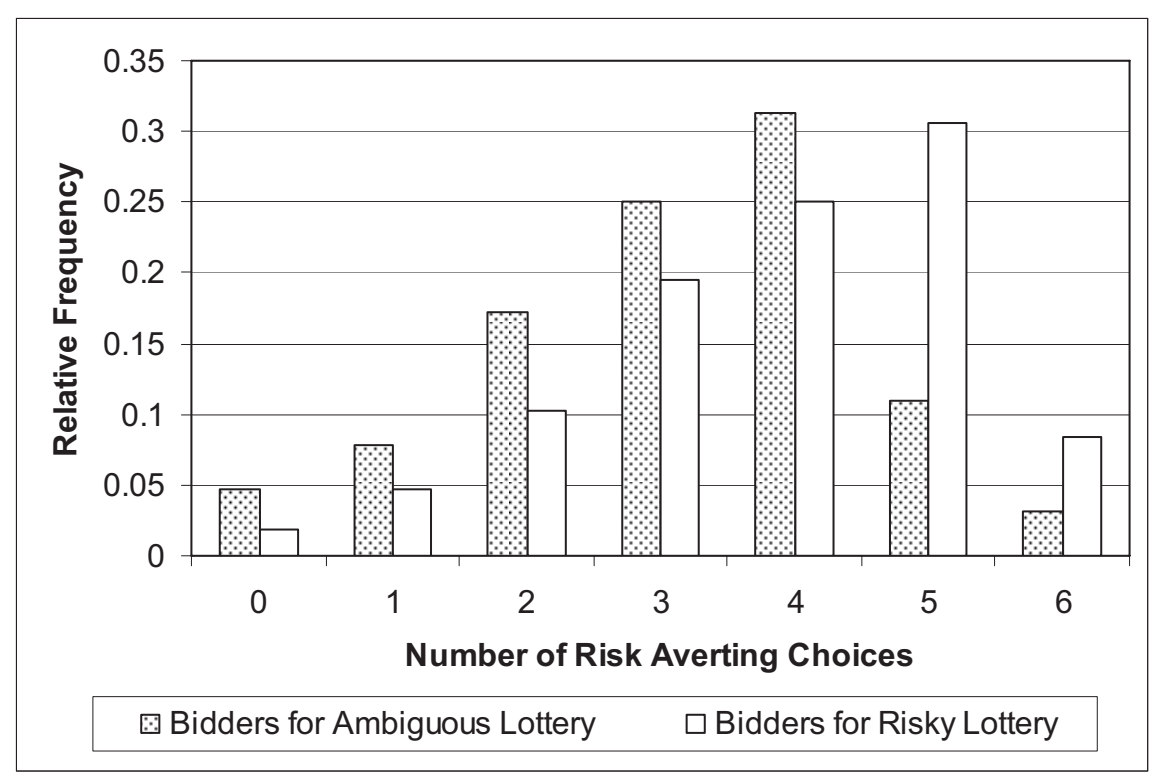

Further evidence that the countervailing effects of risk attitude and expected market size lead to equal transaction prices in the two markets comes from the analysis of the 16 auction winners. The winners of the auction for the risky prospect on average make 3.38 safe choices in the risky decision task, while winners of the ambiguous prospect make only 1.75 safe choices ( $\mathrm{p}=0.062$, Mann-Whitney test). However, the winners of the risky prospect expected strong competition in their auction (score 4.38 , or approximately $75 \%$ of all participants), while the winners of the ambiguous prospect expected relatively low competition (score 2.5 or approximately $40 \%$ of all participants) in their market ( $\mathrm{p}=0.001$, Mann-Whitney test). We conclude that the positive correlation between risk and ambiguity attitude leads to thinner markets with more risk prone subjects in the market for the ambiguous prospect than for the risky prospect. This market segmentation contributes to the equality of transaction prices for the two prospects in our experiment. 
Table 3: Regression Analyses of Auction Choices, Bids, and Transaction Prices

\begin{tabular}{|c|c|c|c|c|}
\hline & Model I & Model II & Model III & Model IV \\
\hline & $\begin{array}{l}\text { Probit }^{\mathrm{b}} \text { : Choice } \\
\text { of market for the } \\
\text { risky prospect }\end{array}$ & $\begin{array}{l}\text { Probit }^{\mathrm{b}} \text { : Choice } \\
\text { of market for the } \\
\text { risky prospect }\end{array}$ & $\begin{array}{l}\text { OLS: Bid for } \\
\text { prospect }\end{array}$ & $\begin{array}{l}\text { OLS: Transaction } \\
\text { price }\end{array}$ \\
\hline Risk aversion & $\begin{array}{l}0.0733^{* *} \\
(0.0269)\end{array}$ & $\begin{array}{l}0.0654^{*} \\
(0.0274)\end{array}$ & $\begin{array}{l}-0.3748^{*} \\
(0.1498)\end{array}$ & \\
\hline $\begin{array}{l}\text { Expected market size } \\
\text { risky prospect }\end{array}$ & & $\begin{array}{l}0.0608 \\
(0.0428)\end{array}$ & & \\
\hline $\begin{array}{l}\text { Expected chance to win } \\
\text { with ambiguous prospect }\end{array}$ & & $\begin{array}{l}-0.1419^{* *} \\
(0.053)\end{array}$ & & \\
\hline $\begin{array}{l}\text { Expected market size own } \\
\text { market }^{\mathrm{a}}\end{array}$ & & & $\begin{array}{l}0.2447 \\
(0.2418)\end{array}$ & \\
\hline Market size & & & & $\begin{array}{l}0.4253^{*} \\
(0.1739)\end{array}$ \\
\hline $\begin{array}{l}\text { Choice of auction for the } \\
\text { risky prospect }\end{array}$ & & & $\begin{array}{l}-0.821 \\
(0.5737)\end{array}$ & $\begin{array}{l}-2.2003 \\
(1.4414)\end{array}$ \\
\hline Female & $\begin{array}{l}0.1116 \\
(0.0788)\end{array}$ & $\begin{array}{l}0.0664 \\
(0.0855)\end{array}$ & $\begin{array}{l}-1.1793 * \\
(0.4564)\end{array}$ & \\
\hline$\#$ of observations ${ }^{c}$ & 172 & 172 & 172 & 16 \\
\hline
\end{tabular}

Robust standard errors in parenthesis; *significant at the 5\%-level, **significant at the $1 \%$-level.

a: Equal to expected market size of the risky prospect for subjects bidding for the risky prospect and equal to one minus this expectation for subjects bidding for the ambiguous prospect.

b: Marginal effects reported.

c: Four subjects did not make a choice in at least one of the independent risky decision tasks and were excluded from the regression analyses.

Effects of Expectations. After submitting their bids, but before learning the result of the auction, we asked subjects to indicate their expectations about the competition in the auction for the risky prospect and about the winning chances with the ambiguous prospect. The latter question is used to approximate in how far subjects perceive the ambiguous prospect as an unattractive option. We would expect that the anticipation of strong competition for the risky prospect makes a bid for the ambiguous prospect more likely. Expecting strong competition in their own market should have a positive effect on subjects' bids in each market. Perceiving the ambiguous prospect as an unattractive option (having low expectations of success when simply playing this option) should make a bid for the risky option more likely.

On average subjects are well-calibrated in their expectations about the competition for the risky prospect. Very few subjects expect more competition for ambiguous, and on the five point scale with brackets of $20 \%$, the average score is 3.8 and the median is 4 . This indicates an expectation of about $65 \%$ choices for the market with the risky prospect (compared to a 
true average value of 63\%). The probit regression in Table 3, Model II, shows however that the effect of beliefs about the competition for the risky prospect is insignificant and points in the wrong direction. If anything, more expected competition for the risky option seems to increase the probability to bid this option. Figure 4 shows that this effect is driven by subjects in the market with the risky prospect holding beliefs of strong competition for this prospect. About $70 \%$ of bidders in the risky auction expect a majority of participants in their own auction, and about $30 \%$ of bidders in the risky auction expect more than $80 \%$ of the participants in their auction. That is, these latter subjects prefer competing with 16 people in the risky market over competing with four people in the ambiguous market.

Figure 4: Auction Choice and Expectations about Competition

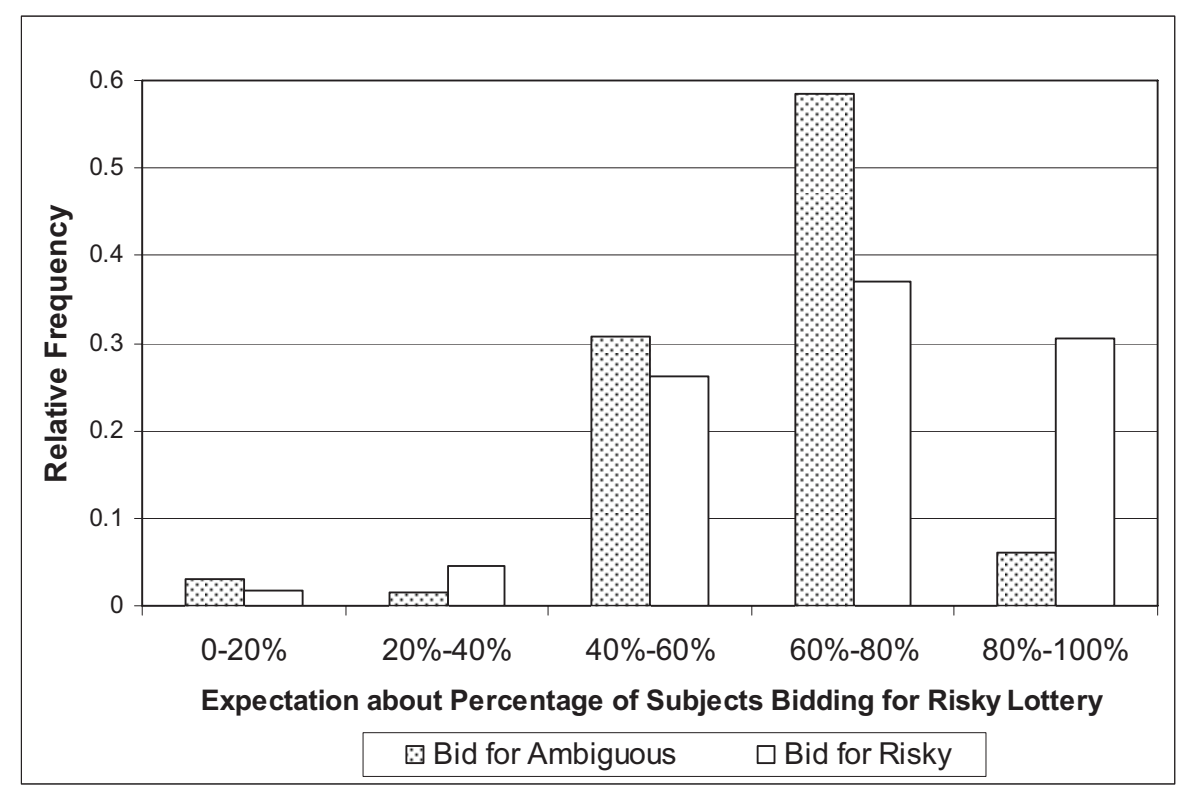

In contrast to the expectations about competition, the attractiveness of the ambiguous option has the expected effect on auction choices. Subjects who perceived the ambiguous prospect as less attractive were more likely to submit a bid for the risky prospect. Figure 5 shows, however, that while few people have a distinctly positive attitude towards ambiguity according to the question about winning chances, extremely negative attitudes are also rare for bidders in both auctions.

Effects of Market Size. Market segmentation in terms of risk attitudes implies that, while transaction prices should be higher in larger markets for either urn, they should be lower for the risky markets when controlling for market size. Model IV of Table 3 reports linear 
regression results showing that an additional bidder in a market increases the transaction price by approximately $€ 0.40$. The transaction price is $€ 2.20$ higher in the ambiguous prospect's markets, but this effect is only marginally significant one-sided.

Figure 5: Expected Winning Chances with Ambiguous

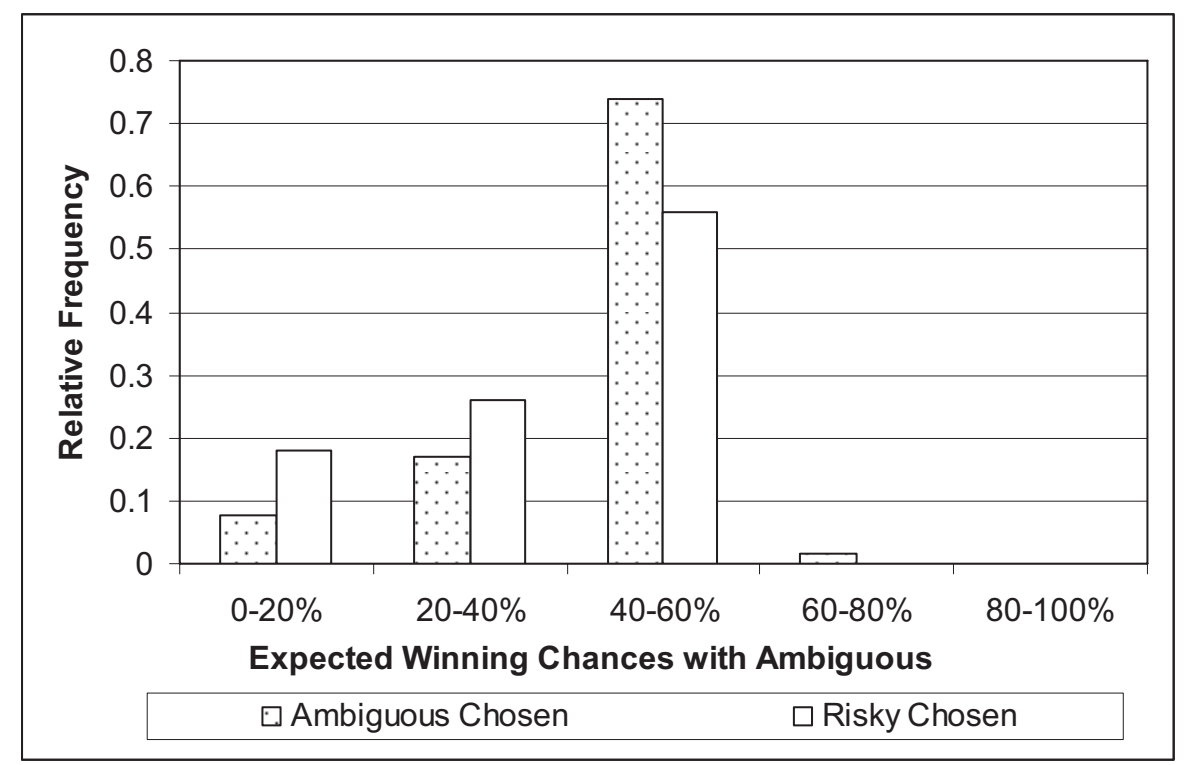

\subsection{Discussion}

We study the effect of selection in first-price auctions and find strong ambiguity aversion leading to smaller markets for ambiguous prospects than for risky prospects, supporting our second hypothesis. There is no support for our first hypothesis regarding the price effects of ambiguity, however: Equal transaction prices are observed in both auctions. These results could be explained by assuming a positive correlation between risk and ambiguity attitudes, and we find indeed that the auctions for the risky prospect are populated by relatively more risk averse bidders than auctions for the ambiguous prospect. Participants correctly anticipate the stronger competition in the risky auctions. Therefore the countervailing effects of bidders' risk attitudes and the expected market sizes seem to have led to equal prices for both prospects. An ambiguity-neutral bidder who perceives both prospects as equally good would be indifferent between bidding for the risky or the ambiguous option in our market. There is no ambiguity premium to earn from the ambiguous prospect over and above the risk premium for the equivalent risky prospect.

We also observe many bidders for the risky prospect expecting strong competition in their auction. These subjects may be extremely ambiguity averse, making the risky prospect 
more attractive despite the fierce competition and the strategic incentives to bid for the ambiguous prospect. Alternatively, they may correctly anticipate the presence of more risk tolerant bidders in the market for the ambiguous prospect, perceiving low chances to win this auction at a cheap price even with little competition. If a company expects few but very aggressive competitors for an ambiguous project in procurement bidding, it may well decide to bid for a less ambiguous project with many, but more cautious competitors. A third explanation may be that subjects simply did not understand the strategic incentives provided by possible differences in market size for the two prospects. Huberman and Rubinstein (2002) find evidence for such strategic mistakes in games where there is no rational explanation for subjects' actions given their beliefs.

In order to distinguish between these explanations, we conducted a control experiment (experiment 2) with selection in a simple choice task that isolates the effect of market size from the effect of others' attitudes.

\section{Experiment 2: Isolating the Effect of Market Size}

\subsection{Design}

Subjects. Another one hundred undergraduate students participated in five laboratory sessions. In each session there were 20 subjects. Students were recruited electronically from the same pool as in experiment 1. Each subject participated only once and had not participated in experiment 1 .

Payoffs. Each subject received a show-up payment of $€ 5$ and could earn approximately $€ 15$ from an unrelated experiment. In each session, two subjects could earn up to $€ 30$ from the choice task described below. The whole experiment took approximately 15 minutes.

Procedure. The stimuli in this experiment were identical to those used in experiment 1, and we used the same descriptions of the risky and ambiguous prospects as in experiment 1 . In each group of 20 participants subjects had to decide whether they wanted to play the risky option $\mathrm{A}$ or the ambiguous option $\mathrm{B}$, under the condition that for each option exactly one subject was randomly selected to play his or her choice for real. That is, subjects' chances to 
be chosen for play depend only on the group sizes for options A and B. Subjects knew the size of the whole group.

Subjects made their decision between option A and option B by choosing one of two decision sheets. On this decision sheet they then made 30 choices in a choice list between sure payoffs and the prospect they had chosen (see Appendix). With this list we elicit the subjects' certainty equivalents (CE) for their chosen option, that is, the sure amount of money that makes subjects indifferent between receiving the sure amount or playing the prospect they have chosen. The certainty equivalent was calculated as the midpoint between the two sure amounts for which a subject switched from preferring the sure money to preferring the prospect.

Subjects handed in their decision sheet in an envelope. One envelope was publicly drawn from the group of subjects choosing option A and one envelope from the group of subjects choosing option B. For these two subjects one of their decisions between a sure amount and their prospect was individually selected by drawing a numbered lot. According to the subject's decision in this choice problem the subject either received the sure amount or played the prospect.

Figure 6: Group Sizes and Maximum Certainty Equivalents in the Choice Task

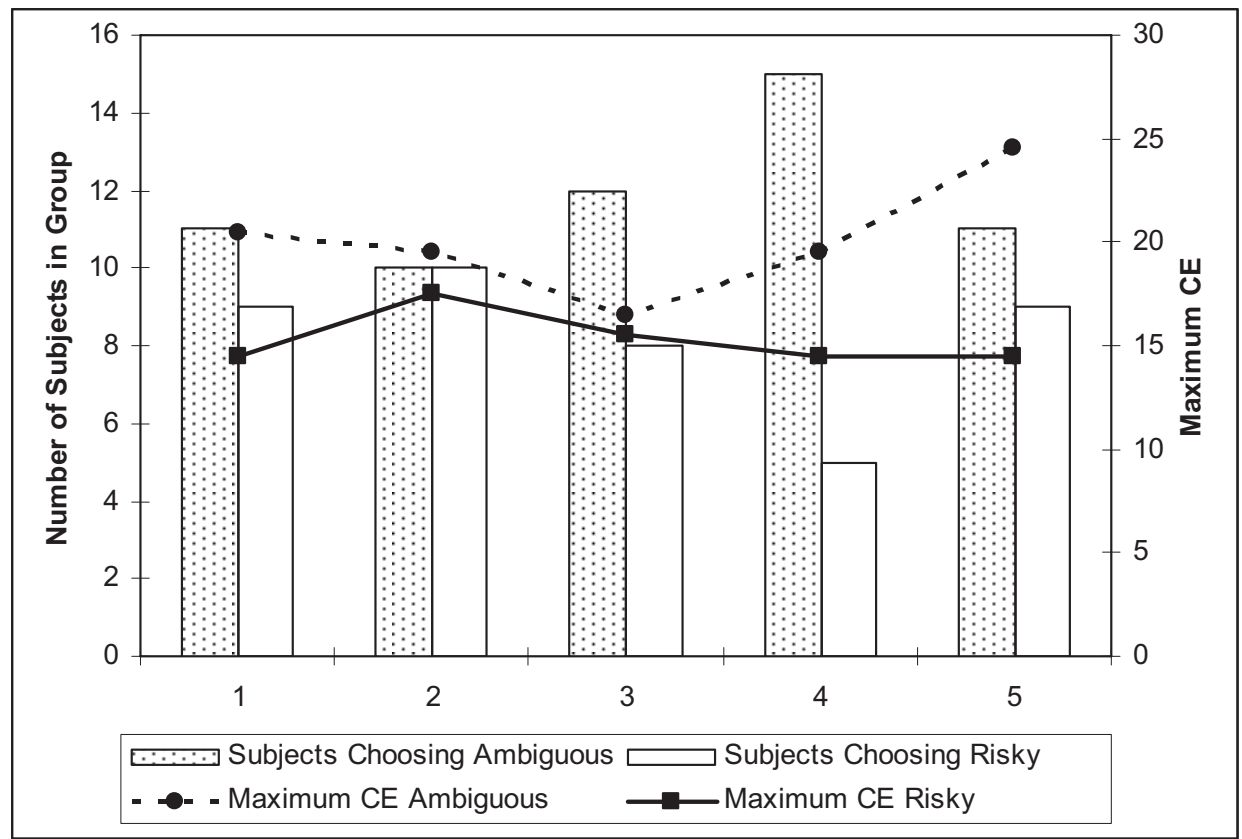




\subsection{Results}

We find that 59 of 100 subjects choose the ambiguous option and we can therefore reject the null hypothesis of thinner markets for ambiguous prospects $(\mathrm{p}=0.044$, binomial test). The details of the five individual sessions are summarized in Figure 6.

The groups choosing the ambiguous option are significantly larger than the groups choosing the risky option ( $\mathrm{p}=0.011$, Mann-Whitney test). In each session, the maximum $\mathrm{CE}$ and the mean $\mathrm{CE}$ for the ambiguous option are larger than for the risky option. Pooling all sessions the mean $\mathrm{CE}$ equals $€ 12.47$ for the ambiguous prospect and $€ 10.82$ for the risky prospect ( $\mathrm{p}=0.07$, Mann-Whitney test).

\subsection{Discussion}

Beliefs about competing bidders' risk attitudes have been shown to affect selection between different auctions (Ivanova-Stenzel and Salmon 2004). Experiment 2 isolates the effect of expectations about market size from the effect of expectations about other bidders' risk attitudes on market choice. In our choice task ambiguity averse subjects have an incentive to choose the ambiguous option if they expect that few people will do so. Low competition increases the chance to be randomly selected to play the ambiguous prospect, making this option more attractive than a low chance to be randomly selected to play the otherwise preferred risky option. In contrast to the market situation in experiment 1 the other participants' risk attitudes do not matter for the choice. In the auction in experiment 1 ambiguity averse subjects might choose to bid in the more competitive risky market if they expect the few bidders in the ambiguous market to be more risk tolerant. Our results from the simple choice task with selection in experiment 2 support this explanation. If other subjects' risk attitudes do not matter because of the random selection for real play, the majority of subjects choose the ambiguous prospect in most sessions.

Consistent with this explanation is the fact that maximum certainty equivalents are indeed larger for the ambiguous prospect in all sessions. The subjects with the maximum CE hold the highest valuation of the uncertain prize in the game, and in an auction these subjects would be among the highest bidders. This explains our observation of equal transaction prices for risky and ambiguous prospects, although markets were much thinner for the ambiguous prospect. 
The observation of larger groups for the ambiguous option in experiment 2 rejects an explanation of market choices in experiment 1 that is based on strategic mistakes as in Huberman and Rubinstein (2002). Subjects react to strategic incentives, but they seem to apply a rather low level of strategic rationality. As shown in experiment 1, most subjects expect the majority of other bidders to be ambiguity averse. In the simple choice task a majority of subjects chooses ambiguous, invalidating these expectations. The results also confirm that ambiguity aversion is widespread, but not overly extreme at the individual level (see Figure 5). If ambiguity aversion were extreme, the higher probability of being selected for play would not make up for the low expectation of winning the prize from ambiguous prospects for most subjects.

Note that subject's decisions in the simple random selection in experiment 2 are not equivalent to decisions in second-price auctions along the lines of experiment 1 . Similar to our incentive compatible CE elicitation of the subjects' valuations of the uncertain prospects, the second price auction elicits true valuations in the bidding stage. ${ }^{6}$ When deciding whether to enter the second-price auction for the risky or the ambiguous prospect, however, both expected market sizes and expected risk attitudes of the other participants matter. Market sizes and others' risk attitudes influence the subject's chances to win the auction and the price the subject has to pay for the prospect if she wins.

The fact that the influence of market size and risk attitudes on winning chances and price must be considered by the subjects in the decision between the prospects, but not in their bid, requires complex reasoning and makes the second-price auction with selection susceptible to errors. The first-price auction in experiment 1 more naturally involves consideration of market size and risk attitudes at both stages.

\footnotetext{
${ }^{6}$ Grimm and Schmidt (2000) show that the second price auction may not elicit true CEs if subjects violate the independence axiom.
} 


\section{General Discussion}

Ambiguity aversion has been used in the explanation of market anomalies, regulatory recommendations and investment strategy. Selection between different market segments has been suggested as an important factor affecting the mechanism by which ambiguity affects market outcomes.

We chose a one-shot first-price auction to study market choices in the presence of ambiguity. This design provides a natural setting for ambiguity with strong strategic incentives. Our experimental data show that ambiguity aversion can persist in competitive markets and can affect market outcomes. This makes ambiguity aversion a potential explanation of market anomalies from the point of view of expected utility theory. Our main experiment finds lower entry into the ambiguous auction, but equal transaction prices for ambiguous and risky auctions. Based on bidders' independently measured risk attitudes, we suggest that heterogeneity in ambiguity attitude and a positive correlation between attitudes toward ambiguity and risk can explain the observed equality in prices.

The existing evidence on the relation between risk and ambiguity aversion is mixed. Cohen, Jaffray and Said (1985) and Curley, Yates and Abrams (1986) find no relation between the two dimensions, and Potamites and Zhang (2007) find a weak positive correlation. These studies do not use independent tasks to measure risk and ambiguity attitude, and they use only a single valuation task to measure each attitude. Presenting risky and ambiguous options jointly in one task will elicit evaluations that are mutually influenced by each other, leading to possibly biased estimates of the correlation. To illustrate the effect, consider a highly risk and ambiguity averse person. Joint evaluation will make the risky option look more attractive because of the presence of the highly unattractive ambiguous option, inducing an artificially high valuation for the risky prospect. The observed degree of risk aversion for this person will be too low, reducing the observed correlation between risk aversion and ambiguity aversion. This effect has been reported by Fox and Tversky (1995, p. 590) and by Halevy (2007, p. 532).

Measuring risk and ambiguity attitude by a single valuation task each is likely to yield data that suffer from measurement error, biasing the correlation between risk and ambiguity attitude downwards (Camerer and Weber 1992). Using independent measures of risk and ambiguity attitude and multiple risky choices to measure risk attitude, Lauriola and Levin (2001) and Lauriola, Levin and Hart (2007) find a significant positive relation between 
ambiguity and risk attitudes. They show that the correlation is largely due to subjects with extreme risk and ambiguity attitudes. Figure 3 shows that this can also be observed in our data. Koch and Schunk (2008) study the effect of liability on the correlation between risk and ambiguity attitude. In particular, they implement treatments where experimental subjects might incur real losses and compare them with treatments where subjects can only lose money from an endowment. Only in the case of real losses (full liability) do they observe a strong correlation between risk and ambiguity attitudes.

Further evidence for a positive correlation comes from investment experiments by Charness and Gneezy (2010) and by Bossaerts et al. (2007). In Charness and Gneezy's study the subjects could invest any fraction of a $\$ 10$ endowment in either a risky prospect or an ambiguous prospect similar to our options $\mathrm{A}$ and B, and keep the rest for sure. If they correctly guessed the color in their chosen prospect, the investment was multiplied by 2.5 . Otherwise the investment was lost. Each subject made an individual decision and there was no strategic interaction. Charness and Gneezy find that the subjects who choose the ambiguous prospect invest significantly more than the subjects who choose the risky prospect.

Bossaerts et al. let their subjects trade in markets for risky and ambiguous state dependent assets and find that those subjects who hold more ambiguous assets also tend to hold more volatile portfolios. They argue that market segmentation in terms of risk and ambiguity attitudes can explain the value premium effect: value stocks tend to have higher returns than growth stocks (Fama and French 1998). If growth stocks are associated with high ambiguity, they attract only ambiguity tolerant investors who are also risk tolerant and therefore require a smaller risk premium than the investors in value stocks.

In our institutional setting, ambiguity leads to market segmentation in terms of risk attitude, and to equal prices for the risky and the ambiguous prospects, although the latter is perceived as less attractive by the majority of subjects. The importance of the market institution for market outcomes in the presence of ambiguity can be illustrated by a comparison of our results with those of Sarin and Weber (1993). Sarin and Weber conducted double-auction markets and first-price sealed bid auctions for risky and ambiguous Ellsberg urn prospects and consistently found lower prices for ambiguous prospects. This price difference can be explained by the fact that a selection of subjects with different ambiguity attitude into the markets for the two prospects was precluded by their market design. All subjects would always participate in each market, holding competition and average risk attitude constant in both markets. The relatively risk tolerant subjects who chose the 
ambiguous prospect in our experiment would bid for the risky prospect in Sarin and Weber's experiment, driving up prices in this market. The relatively risk averse subjects who chose risky in our experiment would have to bid for the ambiguous prospect in Sarin and Weber's experiment. These subjects are also ambiguity averse and therefore unlikely to submit high bids, leaving market prices unaffected. Positively correlated ambiguity and risk attitudes can explain both results when taking the different market institutions into account. The comparison of Sarin and Weber's and our results illustrates the importance of the markets size effect of ambiguity aversion that was emphasized by Easley and O'Hara (2009) and Zeckhauser (2006). It also shows that one has to be careful when extrapolating ambiguity effects from one market institution to another.

The selection effects found in our experiment may be important in license auction markets (Goeree and Offerman 2003; Janssen 2006; Offerman and Potters 2006). The firms competing in these auctions bid for a prize with an uncertain outcome. Assuming that managers are risk averse, it has been shown that auctions have an effect on prices in the aftermarket by selecting the most risk tolerant firms (Janssen and Karamychev 2007). The selection of relatively risk and ambiguity prone firms into auctions for aftermarkets that have more ambiguous payoff distributions implies that this effect is reinforced for ambiguity.

In auctions, and more generally, in markets, the agents' revealed ambiguity attitudes depend on their expectations of other participants' attitudes toward risk and ambiguity. Studying the interaction between agents' expectations and their attitudes toward uncertainty in more complex markets seems, in general, a promising route to improve ambiguity-based explanations of market behavior and the resulting policy recommendations. 


\section{References}

Bossaerts, P., P. Ghirardato, S. Guarnaschelli and W. Zame (2007). Prices and Allocations in Asset Markets with Heterogeneous Attitudes Toward Ambiguity. Review of Financial Studies 23, 1325-1359.

Camerer, C. F. and H. C. Kunreuther (1989). Experimental Markets for Insurance. Journal of Risk and Uncertainty 2, 265-300.

Camerer, C. and M. Weber (1992). Recent Developments in Modeling Preferences: Uncertainty and Ambiguity. Journal of Risk and Uncertainty 5, 325-370.

Charness, G. and U. Gneezy (2010). Portfolio Choice and Risk Attitudes: An Experiment. Economic Inquiry 48, 133-146.

Chen, Y., P. Katuscak and E. Ozdenoren (2007). Sealed Bid Auctions with Ambiguity: Theory and Experiments. Journal of Economic Theory 136, 513-535.

Cohen, M., J. Y. Jaffray and T. Said (1985). Individual Behavior under Risk and Uncertainty: An Experimental Study. Theory and Decision 18, 203-328.

Cox, J., V. L. Smith and J. M. Walker (1982). Auction Market Theory of Heterogeneous Bidders. Economic Letters 9, 319-325.

Cox, J., V. L. Smith and J. M. Walker (1985). Experimental Development of Sealed-Bid Auction Theory: Calibrating Controls for Risk. American Economic Review 75, 160165.

Curley, S. P., J. F. Yates and R. A. Abrams (1986). Psychological Sources of Ambiguity Avoidance. Organizational Behavior and Human Decision Processes 38, 230-256.

Dufwenberg, M. and U. Gneezy (2002). Information Disclosure in Auctions: An Experiment. Journal of Economic Behavior and Organization 48, 431-444.

Easley, D. and M. O’Hara (2009). Ambiguity and Nonparticipation: The Role of Regulation. Review of Financial Studies 22, 1817-1843. .

Ellsberg, D. (1961). Risk, Ambiguity and the Savage Axioms. Quarterly Journal of Economics 75, 643-669.

Esö, P. and L. White (2004). Precautionary Bidding in Auctions. Econometrica 72, 77-92.

Fama, E. F. and K. R. French (1998). Value versus Growth: The International Evidence. Journal of Finance 53, 1975-1999.

Fischbacher, U. (2007). Z-Tree: Zurich toolbox for ready-made economics experiments. Experimental Economics 10, 171-178. 
Fox, C. R. and A. Tversky (1995). Ambiguity Aversion and Comparative Ignorance. Quarterly Journal of Economics 110, 585-603.

Gilboa, I. (2004, ed.). Uncertainty in Economic Theory: A collection of Essays in Honor of David Schmeidler's 65th birthday, Routledge, London.

Goeree, J. K. and T. Offermann (2003). Competitive Bidding in Auctions with Private and Common Values. Economic Journal 113, 598-613.

Grimm, V. and U. Schmidt (2000). Equilibrium Bidding without the Independence Axiom: A Graphical Analysis. Theory and Decision 49, 361-374.

Halevy, Y. (2007). Ellsberg Revisited: An Experimental Study. Econometrica 75, 503-536.

Haruvy, E., Y. Lahav, and C. N. Noussair (2007). Traders' Expectations in Asset Markets: Experimental Evidence. American Economic Review 97, 1901-1920.

Hogarth R. M. and H. C. Kunreuther (1985). Ambiguity and Insurance Decisions. American Economic Review 75, 386-390.

Holt, C. A. and S. K. Laury (2002). Risk Aversion and Incentive Effects. American Economic Review 92, 1644-1655.

Huang, R. R. (2007). Distance and Trade: Disentangling Unfamiliarity Effects and Transport Cost Effects. European Economic Review 51, 161-181.

Huberman, G. and A. Rubinstein (2002). Correct Belief, Wrong Action. Working Paper, Columbia Business School.

Ivanova-Stenzel, R. and T. C. Salmon (2004). Bidder Preferences Among Auction Institutions. Economic Inquiry 42, 223-236.

Ivanova-Stenzel, R. and T. C. Salmon (2008). Robustness of Bidder Preferences Among Auction Institutions. Economic Inquiry 46, 355-368.

Iyer, G., and A. Pazgal (2008). Procurement Bidding with Restrictions. Quantitative Marketing and Economics 6, 177-204.

Jamison, J. and D. S. Karlan (2009). When Curiosity Kills the Profits: An Experimental Examination. Games and Economic Behavior 66, 830-840.

Janssen, M. C. W. (2006). Auctions as Coordination Devices. European Economic Review $50,517-532$.

Janssen, M. C. W. and V. A. Karamychev (2007). Selection Effects in Auctions for Monopoly Rights. Journal of Economic Theory 134, 576-582. 
Kahn, B. E. and R. K. Sarin (1988). Modeling Ambiguity in Decisions under Uncertainty. Journal of Consumer Research 15, 265-272.

Keynes, J. M. (1921). A Treatise on Probability. MacMillan, London.

Knight, F. H. (1921). Risk, Uncertainty, and Profit. University of Chicago Press, Chicago.

Koch, C. and D. Schunk (2008). Limiting Auditors' Liability? - Experimental Evidence on Behavior under Risk and Ambiguity. Working Paper, University of Zurich.

Lauriola, M. and I. P. Levin (2001). Relating Individual Differences in Attitude Toward Ambiguity to Risky Choices. Journal of Behavioral Decision Making 14, 107-122.

Lauriola, M., I. P. Levin and S. S. Hart (2007). Common and Distinct Factors in Decision Making under Ambiguity and Risk: A Psychometric Study of Individual Differences. Organizational Behavior and Human Decision Processes 104, 130-149.

Muthukrishnan, A.V., L. Wathieu, and A. J. Xu (2009). Ambiguity Aversion and Persistent Preference for Established Brands. Management Science 55, 1933-1941.

Neugebauer, T. and R. Selten (2006). Individual Behavior of First-price Auctions: The Importance of Information Feedback in Computerized Experimental Markets. Games and Economic Behavior 54, 183-204.

Ockenfels, A. and R. Selten (2005). Impulse Balance Equilibrium and Feedback in First Price Auctions. Games and Economic Behavior 51, 155-170.

Offerman, T. and J. Potters (2006). Does Auctioning of Entry Licenses Induce Collusion? An Experimental Study. Review of Economic Studies 73, 769-791.

Potamites, E. and B. Zhang (2007). Measuring Ambiguity Attitudes: a field experiment among small-scale stock investors in China. Working paper, New York University.

Salo, A. A. and M. Weber (1995). Ambiguity Aversion in First-Price Sealed Bid-Auctions. Journal of Risk and Uncertainty 11, 123-137.

Sarin, R. K. and M. Weber (1993). Effects of Ambiguity in Market Experiments. Management Science 39, 602-615.

Savage, L. J. (1954). The Foundations of Statistics. Wiley, New York.

Snow, A. and R. S. Warren, Jr. (2005). Ambiguity about Audit Probability, Taxpayer Compliance, and Taxpayer Welfare. Economic Inquiry 43, 865-871.

Starmer, C. and R. Sugden (1991). Does the Random-Prospect Incentive System Elicit True Preferences? An Experimental Investigation. American Economic Review 81, 971-978. 
Uppal, R. and T. Wang (2003). Model Misspecification and Underdiversification. Journal of Finance 58, 65-92.

Van de Kuilen, G. (2009). Subjective Probability Weighting and the Discovered Preference Hypothesis. Theory and Decision 67, 1-22.

Wakker, P. P., D. R. M. Timmermans and I. A. Machielse (2007). The Effects of Statistical Information on Risk and Ambiguity Attitudes, and on Rational Insurance Decisions. Management Science 53, 1770-1784.

Zeckhauser, R. (2006). Investing in the Unknown and Unknowable. Capitalism and Society 1, Article 5. 


\section{Appendix: Experimental Instructions}

\section{Extra Gamble Options!}

We offer you the following extra gamble options before the payoffs of the experiment are determined and you receive your payoffs. Please read the descriptions carefully!

Option A gives you a draw from a bag that contains exactly 20 red and 20 green poker chips. Before you draw, you choose a color and announce it to the experimenter. Then you draw. If the color you announced matches the color you draw, you win $€ 30$. If the colors do not match, you get nothing.

Option B gives you a draw from a bag that contains exactly 40 poker chips. They are either red or green, in an unknown proportion. Before you draw, you choose a color and announce it to the experimenter. Then you draw. If the color you announced matches the color you draw, you win $€ 30$. If the colors do not match, you get nothing.

\section{[In experiment 1 the instructions proceeded as follows:]}

We offer only one option A and one option B to the whole group. We will determine the persons who play the options by an auction for each of the options. If you would like to play either of these options, you have to buy the right to play it from your own cash by making the largest bid for this option. If your bid wins the auction you have to pay your bid immediately and cannot use advance payments from possible earnings from the experiment. If there is more than one highest bid, the computer randomly determines one person as the winner of the auction.

You can place a bid for one option only! Thus you must decide for which option to bid and how much to bid for that option! You bid only once and privately, there are no repeated bids.

\section{Procedure:}

On the following screen you will first choose whether you want to bid for Option A or Option B.

Then you will submit a bid in Euro and Cent for that option. You can bid every amount between $0.00 €$ and $30.00 €$.

If you do not want to bid from your own money for the option to play one of the gambles, choose one option and make a bid of zero Euros. If there is no positive bid in this auction, you may still win and play with a zero bid.

The auction winners for Options A and Option B are determined. An experimenter will come to each auction winner, collect the bid (we can change money if needed) and play the gamble. If the color matches, the person immediately receives $30 €$. If the colors do not match, the person does not receive any payoff. 


\section{[In experiment 2 the instructions proceeded as follows:]}

We offer only one option A and one option B to the whole group. We will determine the persons who play the options as follows:

Each participant chooses which option he or she prefers to play. We will randomly draw one person from the participants who chose option A and give him or her the opportunity to play option A. We also randomly draw one person from the group of participants who chose option B and give him or her the opportunity to play option B.

Please read the instructions carefully and then make a choice whether you want to play option A or option B.

- If you want to play option $A$ (bet on a color to win $€ 30$ from bag with 20 red and 20 green chips), open the envelope with the letter 'A' on it and fill out the sheet in there.

- If you want to play option B (bet on a color to win $€ 30$ from bag with unknown proportion of colors), open the envelope with the letter 'B' on it and fill out the sheet in there.

Please leave the envelope of the option you do not choose closed.

\section{Decision Sheet Option A.}

You want to play option A (bet on a color to win $€ 30$ from bag with 20 red and 20 green chips)

We offer you the following: for each of the choices on the back of this sheet you decide whether you want to play option A or receive a sure amount instead. If you are randomly selected for real play from the people who chose option A, the experimenter will come to your desk and you will draw a lottery number to determine which of the choices on the back will be played [indicated by the number in brackets left to the choice option].

Depending on your decision in this choice you will either play option A as described before, or immediately receive the sure amount.

Example 1. You were selected for real play. You draw number ' 30 '. For this number you made the following decision:

[30] Play Option A $\quad$ O $\quad$ or $\quad * \quad$ get $€ 30$ for sure

You chose the sure amount here. Therefore you immediately receive $€ 30$. You will not play the gamble.

Example 2. You were selected for real play. You draw number ' 1 '. For this number you made the following decision:
Play Option A
ג
or
O get $€ 1$ for sure

You chose to play the gamble here. Therefore you play the gamble as described and if you match the colors you get $€ 30$, otherwise you get nothing.

Only one number will be drawn, that is, only one of the thirty choices will be played. Make sure that for each choice you make a decision that is in your best interest because this choice might be the payoff relevant choice that determines your payoff!

Please give your desk number here:

Please also indicate your gender: $\mathrm{O}$ female $\mathrm{O}$ male 
Fill out all 30 choices on the back now. Then the decision sheets will be collected. One person will be drawn from each group (option A choosers and option B choosers) and we play one randomly selected choice with them.

When we come to collect the sheets, please hand in your decision sheet in the envelope. Leave all other sheets on your desk.

Option A (bet on color from bag with 20 red and 20 green chips to win $€ 30$ ) or sure amount of $€$ :

\begin{tabular}{|c|c|c|c|c|c|}
\hline [1] & Play Option A & $\mathrm{O}$ & or & $\mathrm{O}$ & get $€ 1$ for sure \\
\hline [2] & Play Option A & $\mathrm{O}$ & or & $\mathrm{O}$ & get $€ 2$ for sure \\
\hline [3] & Play Option A & $\mathrm{O}$ & or & $\mathrm{O}$ & get $€ 3$ for sure \\
\hline [4] & Play Option A & $\mathrm{O}$ & or & $\mathrm{O}$ & get $€ 4$ for sure \\
\hline [5] & Play Option A & $\mathrm{O}$ & or & $\mathrm{O}$ & get $€ 5$ for sure \\
\hline [6] & Play Option A & $\mathrm{O}$ & or & $\mathrm{O}$ & get $€ 6$ for sure \\
\hline [7] & Play Option A & $\mathrm{O}$ & or & $\mathrm{O}$ & get $€ 7$ for sure \\
\hline [8] & Play Option A & $\mathrm{O}$ & or & $\mathrm{O}$ & get $€ 8$ for sure \\
\hline [9] & Play Option A & $\mathrm{O}$ & or & $\mathrm{O}$ & get $€ 9$ for sure \\
\hline [10] & Play Option A & $\mathrm{O}$ & or & $\mathrm{O}$ & get $€ 10$ for sure \\
\hline [11] & Play Option A & $\mathrm{O}$ & or & $\mathrm{O}$ & get $€ 11$ for sure \\
\hline [12] & Play Option A & $\mathrm{O}$ & or & $\mathrm{O}$ & get $€ 12$ for sure \\
\hline [13] & Play Option A & $\mathrm{O}$ & or & $\mathrm{O}$ & get $€ 13$ for sure \\
\hline [14] & Play Option A & $\mathrm{O}$ & or & $\mathrm{O}$ & get $€ 14$ for sure \\
\hline [15] & Play Option A & $\mathrm{O}$ & or & $\mathrm{O}$ & get $€ 15$ for sure \\
\hline [16] & Play Option A & $\mathrm{O}$ & or & $\mathrm{O}$ & get $€ 16$ for sure \\
\hline [17] & Play Option A & $\mathrm{O}$ & or & $\mathrm{O}$ & get $€ 17$ for sure \\
\hline$[18]$ & Play Option A & $\mathrm{O}$ & or & $\mathrm{O}$ & get $€ 18$ for sure \\
\hline [19] & Play Option A & $\mathrm{O}$ & or & $\mathrm{O}$ & get $€ 19$ for sure \\
\hline [20] & Play Option A & $\mathrm{O}$ & or & $\mathrm{O}$ & get $€ 20$ for sure \\
\hline [21] & Play Option A & $\mathrm{O}$ & or & $\mathrm{O}$ & get $€ 21$ for sure \\
\hline [22] & Play Option A & $\mathrm{O}$ & or & $\mathrm{O}$ & get $€ 22$ for sure \\
\hline [23] & Play Option A & $\mathrm{O}$ & or & $\mathrm{O}$ & get $€ 23$ for sure \\
\hline [24] & Play Option A & $\mathrm{O}$ & or & $\mathrm{O}$ & get $€ 24$ for sure \\
\hline$[25]$ & Play Option A & $\mathrm{O}$ & or & $\mathrm{O}$ & get $€ 25$ for sure \\
\hline [26] & Play Option A & $\mathrm{O}$ & or & $\mathrm{O}$ & get $€ 26$ for sure \\
\hline [27] & Play Option A & $\mathrm{O}$ & or & $\mathrm{O}$ & get $€ 27$ for sure \\
\hline [28] & Play Option A & $\mathrm{O}$ & or & $\mathrm{O}$ & get $€ 28$ for sure \\
\hline [29] & Play Option A & $\mathrm{O}$ & or & $\mathrm{O}$ & get $€ 29$ for sure \\
\hline [30] & Play Option A & $\mathrm{O}$ & or & $\mathrm{O}$ & get $€ 30$ for sure \\
\hline
\end{tabular}

[Analogously for option B] 